\title{
O ENSINO SECUNDÁRIO E A FORMAÇÃO DAS ELITES
}

\section{Rosa Fátima de Souza-Chaloba ${ }^{1}$} Norberto Dallabrida ${ }^{2}$

\section{A historiografia nacional e internacional da educação tem posto em re- 1 levo o caráter elitista do ensino secundário, predominante desde o seu} nascimento até a primeira metade do século XX, evidenciado no reduzido número de escolas e de alunos matriculados, nas políticas discricionárias voltadas para esse ramo de ensino e nas finalidades orientadas para a seletividade materializadas no currículo. Como "o todo poderoso império do meio" (FEBVRE, 1939 apud LUC, 2005), o ensino secundário identificou-se como uma estratégia cultural das elites, que visava sua modernização e reprodução. Na perspectiva sociológica bourdieusiana, a realização do ensino secundário era uma acumulação de capital cultural no estado incorporado, porque proporcionava a aquisição de uma cultura distinta, formada pela Língua Portuguesa e outros idiomas clássicos e modernos; conhecimentos científicos matemáticos e saberes artísticos; e no estado institucionalizado devido ao fato de conferir um diploma que viabilizava o ingresso no ensino superior. Segundo Bourdieu (1998), a passagem pelo longo e seleto ensino secundário, às vezes em regime de internato ou semi-internato, acumulava capital social, isto é, uma rede de

\footnotetext{
1 Professora titular de História da Educação da Universidade Estadual Paulista (UNESP), campus de Araraquara. E-mail: rosa.souza@unesp.br

2 Professor titular da Universidade do Estado de Santa Catarina (UDESC), campus de Florianópolis. E-mail: norbertodallabrida@gmail.com
} 
relações sociais que era atualizada, sobretudo, por associações de ex-alunos e poderia ser útil em suas trajetórias socioprofissionais. Desta forma, o ensino secundário de corte elitista concorreu para a (re)produção social.

Em direção oposta ao ensino primário, propugnado em toda parte como nível de escolarização destinado ao povo, por excelência, o ensino secundário firmou-se, no século XIX, como um grau intermediário entre o primário e o superior, consolidando uma educação da juventude com características sociais e culturais específicas. Isto é, uma formação fundada nas humanidades clássicas e literárias, com forte ênfase no Latim, abarcando uma cultura geral desinteressada, indiferente aos conhecimentos úteis em relação ao mundo do trabalho e muito vinculada ao ensino superior. Dessa maneira, a trajetória do secundário desenvolveu-se à parte dos sistemas nacionais de ensino e das ideias de universalização da escola pública. Ele configurou-se como uma fronteira sociocultural, ou seja, uma educação marcada pela distinção, preconizando a formação do homem cultivado e civilizado, apreciador da elegância e do bom gosto, da arte de expressão (o escrever e falar bem) e da estética literária. Além de proporcionar conhecimentos diferenciados, “o todo poderoso império do meio" (FEBVRE, 1939 apud LUC, 2005) conferia ao estudante secundarista uma hexis corporal própria das classes dominantes.

Nutrindo-se dessa especificidade, a expansão do secundário foi lenta na Europa e na América Latina, reforçando ainda mais sua elitização. No Brasil, por exemplo, foram poucos os colégios mantidos pelo poder público até a década de 1930, predominando a privatização e a presença marcante da Igreja Católica. Segundo Bruneau (1974, p. 122), em 1931, mais de três quartos das escolas secundárias brasileiras pertenciam à rede católica. Em 1939, havia 629 estabelecimentos de ensino secundário no Brasil, sendo 530 particulares e 99 públicos. Quase um terço das escolas estava no estado de São Paulo (196), que detinha, também, quase a metade das escolas públicas do país (43) (SCHWARTZMAN; BOMENY; COSTA, 2000). Em 1955, Jayme Abreu, técnico 
do Inep (Instituto Nacional de Pesquisas Educacionais), em um estudo apresentado no Seminário Interamericano de Educação Secundária, realizado em Santiago/Chile, assinalou o conservadorismo predominante nas instituições escolares brasileiras, o flagrante desajuste entre os princípios de escola para a classe dominante, imperante no país, e a gradual expansão em curso.

Segundo esse autor, em 1954, a matrícula geral do secundário no país fora igual a 535.775 alunos espalhados por 1.771 escolas. Esse número de matriculados correspondia a apenas 6\% da população escolar (idade entre 12 e 18 anos), a qual foi estimada em 9.100 .000 habitantes. Em relação às entidades mantenedoras, havia 435 escolas públicas de ensino secundário (19 federais, 348 estaduais, 68 municipais) e 1.336 particulares. Nas escolas públicas estavam matriculados 143.465 alunos, correspondendo a 26,8\% do alunado, enquanto a rede particular atendia 392.310 alunos, equivalente a 73,2\% dos matriculados (ABREU, 1955, p. 32-33).

Além das dificuldades de acesso interpostas pelo reduzido número de instituições, geralmente concentradas nas capitais dos estados e nos núcleos urbanos maiores, e pelo alto custo das taxas escolares, outras desigualdades caracterizaram o ensino secundário no país, como as diferenças de matrícula entre homens e mulheres, a distribuição desigual de escolas pelas diferentes regiões e a exclusão de negros e indígenas. De outra parte, é importante colocar o foco na assimetria entre os dois ciclos do ensino secundário que se colocou no sistema de ensino brasileiro a partir do início dos anos 1930. Assim, a Reforma Francisco Campos (1931) passou a dividir o ensino secundário em fundamental (cinco anos) e complementar (dois anos), que foi reestruturado pela Lei Orgânica do Ensino Secundário (Reforma Capanema de 1942), passando a ter, até 1971, o curso ginasial (quatro anos) e o colegial três anos), sendo que este último ciclo era bifurcado em científico e clássico. Se o primeiro ciclo do ensino secundário era mais acessível aos estudantes e, em boa medida, dava formação para o ingresso no mercado de trabalho, o segundo ciclo era 
mais seletivo e frequentado prioritariamente por jovens homens. Verifica-se, portanto, um elitismo mais aprofundado e de caráter masculinista nos cursos complementar, científico e clássico que conduziam ao ensino superior.

A expansão do secundário e sua progressiva transformação de uma escola de elite para uma escola popular concretizou-se, efetivamente, na segunda metade do século XX. Para o mundo ocidental, um texto fundador foi o Plano Langevin-Wallon (1947), que defendia o alargamento da escolarização para todos os cidadãos até os 18 anos, o que incluía o ensino secundário (BERRIO, 1996). Este plano ousado não foi aplicado no sistema de ensino francês, mas tornou-se uma referência na França e no mundo ocidental. Nesta direção, nos anos de 1950, o Brasil passou por um crescimento inédito do ensino secundário, mas a divisão entre os cursos técnicos - comercial, industrial e agrícola -, o curso normal e o ensino secundário propedêutico, em boa medida reforçado pela Lei Orgânica do Ensino Secundário, foi pautada pela longa discussão sobre a Lei de Diretrizes e Bases da Educação Nacional (LDB). A equiparação efetiva desses cursos, definida pela LDB de 1961, contribuiu para o início da massificação do ensino secundário, que se verificou a partir da década de 1960, particularmente promovida pelos sistemas estaduais de ensino. No entanto, à medida que avançam as pesquisas sobre o tema, noções de elite e elitização têm sido confrontadas com a história das instituições e das políticas específicas de democratização do ensino.

Os artigos reunidos neste dossiê problematizam diferentes dimensões elitizadoras do ensino secundário e as resistências a elas. O texto inicial do dossiê, de Vera Lúcia Nogueira, mostra como a questão do secundário já era polêmica desde a construção do Estado-nação no Brasil. A autora analisa os debates e disputas entre o Estado e a Igreja acerca da organização e institucionalização do secundário na província de Minas Gerais no período imperial. Tomando como objeto a gênese da criação do primeiro colégio público da província, o Collegio de Nossa Senhora de Assumpção, no decurso das décadas de 1830 a 
1840, o texto explora como atores políticos e religiosos disputaram o controle pela formação intelectual e moral da juventude mineira.

O artigo de Pablo Pineau discorre sobre o modelo meritocrático instituído no Colegio Nacional de Buenos Aires anexado à Universidade de Buenos Aires, na década de 1910, no contexto da modernização levada a termo na Argentina no início do século XX. O novo modelo, em reação ao padrão oligárquico, buscou atender às exigências da democratização social e educativa. No entanto, diversos aspectos como o currículo, o edifício majestoso e os exames de ingresso vinculados à universidade acabaram por reafirmar o caráter elitista do colégio, consolidando uma nova distinção.

O foco do artigo elaborado por Leoncio López-Ocón Cabrera são as reformas educacionais levadas a termo na Espanha no período de 1931-1936, com vistas à renovação do secundário, tornando-o menos elitista. O autor examina duas estratégias utilizadas pelo Estado: o aumento do número de escolas com a ampliação de oportunidades educacionais para as mulheres e a disseminação de novos métodos de ensino com base na metodologia ativa.

O ensino secundário feminino em Goiás é objeto do artigo de Roselene Candida Barros Mendonça e Sandra Elaine Aires de Abreu. A reconstituição da história do Ginásio Auxilium, criado na cidade de Anápolis, em 1943, possibilitou às autoras verificarem a composição do alunado da escola, constituído por moças de famílias privilegiadas do município e região. No que diz respeito à proposta pedagógica da instituição, mesmo propondo uma educação secundária mais moderna, as práticas educativas priorizavam uma preparação que reafirmava o papel social da mulher voltado para o lar.

As mudanças ocorridas no ensino secundário no Brasil, nas décadas finais do século XX, causadas pelo avanço da democratização das oportunidades educacionais nessa modalidade de ensino são problematizadas no artigo de Samuel Luís Velásquez Castellanos e Wilson Raimundo de Oliveira, por meio da 
investigação da trajetória do Colégio Universitário da Universidade Federal do Maranhão. A passagem de uma fase de elitização (1968-1980), abarcando a criação do colégio e seu funcionamento em prédios do centro histórico da cidade de São Luís, capital do estado do Maranhão, para uma fase de popularização (1980-2006), quando a escola passa a funcionar em um bairro popular, é abordada pelos autores, os quais ressaltam as tensões entre a cultura veiculada pela instituição e a cultura da comunidade escolar atendida.

Por último, o texto de Fernando Vendrame Menezes chama atenção para uma questão importante para a historiografia do ensino secundário, isto é, o modo como a noção de elite vem sendo utilizada. Adotando uma perspectiva histórico-comparada, o autor questiona o pressuposto implicado na relação entre ensino secundário e formação das elites, adotado na produção de dissertações e teses, sem o devido aprofundamento conceitual e empírico em torno da caracterização dos alunos e alunas das escolas secundárias ao longo do tempo.

Acreditamos que a questão da elitização do ensino secundário é muito oportuna no momento histórico plasmado pela pandemia do novo coronavírus e do movimento antirracista, cujo epicentro foi nos EUA, mas que também tem escala global. Esses processos contemporâneos recolocaram no centro da pauta as desigualdades sociais e escolares e nos fazem reler o passado.

\section{Referências}

ABREU, Jayme. A educação secundária no Brasil (Ensaios de identificação de suas características principais). n. 9. Rio de Janeiro: MEC/CILEME, 1955.

BERRIO, Julio Ruiz. Proyecto de Reforma de la Enseñanza Langevin-Wallon. In: BERRIO, Julio Ruiz (Ed.). La educación en los tiempos modernos. Madrid: Editorial: Actas, 1996. p. 328-333.

BOURDIEU, Pierre. Escritos de educação. Seleção, organização, introdução e notas de Maria Alice Nogueira e Afrânio Catani. Petrópolis: Vozes, 1998. 
BRUNEAU, Thomas. O catolicismo brasileiro em época de transição. São Paulo: Loyola, 1974.

LUC, Jean-Noël. À la recherche du "tout puissant empire du milieu”: l'histoire des lycées et leur historigraphie. In: CASPARD, Pierre; LUC, Jean-Noël; SAVOIE, Philippe. Lycées, lycéens, lycéennes: deux siècles d'histoire. Paris: Institut National de Recherche, 2005. p.11-56.

SCHWARTZMAN, Simon; BOMENY, Helena Maria Bousquet; COSTA, Vanda Maria Ribeiro. Tempos de Capanema. Rio de Janeiro: Paz e Terra; São Paulo: Edusp, 2000. 